\title{
Akne Vulgarisli Hastalarda İotretinoin Kullanımının Anksiyete ve Depresyon Skorlarına Etkisi
}

\section{The Effect of Isotretinoin Administration on Anxiety and Depression Scores in Patients with Acne Vulgaris}

\author{
Hatice Nur Azaklı, Emine Derviș, Illknur Altunay*, Sinem Gönenli** \\ Haseki Eğitim ve Araștırma Hastanesi, Deri ve Zührevi Hastalıklar Kliniği, İstanbul, Türkiye \\ *Șișli Etfal Eğitim ve Araștırma Hastanesi, Dermatoloji Kliniği ve **Psikiyatri Kliniği, İstanbul, Türkiye
}

\section{Özet}

Amaç: Bu çalıșmada akne vulgaris tedavisinde kullanılan izotretinoinin depresyon ve anksiyete ölçeği skorları üzerine etkisine bakarak depresyon ve anksiyete semptomlarına neden olup olmadığının saptanması amaçlandı.

Gereç ve Yöntemler: Çalıșmaya 2007-2009 yılları arasında Haseki Eğitim ve Araștırma Hastanesi Dermatoloji polikliniğine bașvuran, 1636 yașları arasında, daha önce çeșitli topikal akne preparatlarına veya sistemik antibiyotik tedavilerine tatmin edici yanıt vermemiș, klinik șiddeti Allen-Smith Skalası'na göre grade 4 ile grade 8 arasında olan ve izotretinoin kullanımı endikasyonu konan 29'u erkek, 60'ı kadın, 89 akne vulgaris olgusu dahil edildi. Hastalara tedavi öncesinde ve 16 haftalık tedavinin bitiminde, toplam 2 kere Hastane Anksiyete ve Depresyon Ölçeği uygulandı.

Bulgular: Çalıșmanın sonuçlarına göre izotretinoin kullanan hastaların tedavi öncesi ve tedavi sonrası anksiyete ve depresyon sıklığı ve tedavi öncesi ve tedavi sonrası anksiyete ve depresyon skorları arasında istatistiksel olarak anlamlı bir fark yoktu $(p>0,05)$.

Sonuç: Bu çalıșmadan elde ettiğimiz veriler izotretinoin ile depresyon ilișkisini desteklememektedir. (Türkderm 2012; 46: 29-32) Anahtar Kelimeler: Akne vulgaris, izotretinoin, anksiyete, depresyon

\section{Summary}

Background and Design: In this study, we aimed to determine whether isotretinoin, used in the treatment of acne vulgaris, causes depression and anxiety symptoms by evaluating its effect on depression and anxiety scale scores.

Materials and Methods: Eighty-nine acne vulgaris patients (F/M: 60/29, age range: 16-36 years), who had attended the outpatient clinic of the Department of Dermatology at Haseki Education and Research Hospital between 2007 and 2009, were enrolled in the study. The clinical severity of acne vulgaris was between grade 4 and grade 8 according to Allen-Smith Scale. All patients were unresponsive to several previously applied topical acne preparations or systemic antibiotics treatments and had indication for isotretinoin use. The Hospital Anxiety and Depression Scale was administered to all patients twice; before and at the end of 16-week treatment.

Results: There was no significant difference between pre- and post-treatment anxiety and depression frequency and scores in patients treated with isotretinoin $(\mathrm{p}>0.05)$.

Conclusion: The findings of the present study do not support the presence of association between isotretinoin and depression. (Turkderm 2012; 46: 29-32)

Key Words: Acne vulgaris, isotretinoin, anxiety, depression

\section{Giriş}

İotretinoin akne patogenezinde rol oynayan bütün faktörlere etkili tek ilaçtır ${ }^{1}$. Şiddetli nodülokistik akne dışında, topikal ve diğer geleneksel tedavilere yanıt vermeyen, skar oluşumuna neden olan, psikolojik olarak problem yaratan akne formlarında ve şiddetli seborede yaygın olarak kullanılmaktadır2,3. İotretinoin ve depresyon arasındaki ilişki halen tartışmalı bir konudur. Toplumdaki depresyon insidansının yüksek olması, izotretinoin gibi başka nedenlerle tetiklenen depresyonların ayırt

Yazıșma Adresi/Address for Correspondence: Dr. Hatice Nur Azaklı, Haseki Eğitim ve Araștırma Hastanesi, Deri ve Zührevi Hastalıklar Kliniği, Istanbul, Türkive Tel.: +90212529 4400 GSM: +90 5058154433 E-posta: cenuraz@hotmail.com Geliş Tarihi/Received: 08.02.2010 Kabul Tarihi/Accepted: 12.07.2011

Türkderm-Deri Hastalıkları ve Frengi Arșivi Dergisi, Galenos Yayınevi tarafindan basılmıștır. Turkderm-Archives of the Turkish Dermatology and Venerology, published by Galenos Publishing. 
edilmesinde güçlüğe neden olmaktadır. Biz bu çalışmamızda kliniğimize akne vulgaris şikayetiyle başvuran ve izotretinoin tedavisi verilen hastalara tedavisi öncesinde ve sonrasında Hastane Anksiyete ve Depresyon Ölçeği (HAD) uygulayarak; izotretinoinin anksiyete ve depresyon yan etkisinin olup olmadığını saptamayı amaçladık.

\section{Gereç ve Yöntem}

2007-2009 yılları arasında hastanemiz dermatoloji polikliniğine başvuran, 16-36 yaşları arasında, daha önce çeşitli topikal akne preparatlarına veya sistemik antibiyotik tedavilerine tatmin edici yanıt vermemiş, klinik şiddeti Allen-Smith Skalası'na göre grade 4 ile grade 8 arasında olan ve izotretinoin kullanımı endikasyonu konan 29'u erkek, 60'ı kadın, 89 akne vulgaris (AV) olgusu çalışma kapsamına alındı.

Gebelik, laktasyon, karaciğer fonksiyon bozukluğu, hiperlipidemi, aterosklerotik kalp hastalığı öyküsü, izotretinoin ile etkileşen ilaç (A vitamini, tetrasiklin, minosiklin, asitretin, karbamazepin, etretinat, deksametazon, balık yağı ürünleri) kullanım öyküsü olan hastalar çalışmaya dahil edilmedi. Daha önce psikiyatrik bir hastalık öyküsü bulunan veya psikiyatik bir hastalık nedeniyle ilaç kullanan hastalar da çalışmaya dahil edilmedi. İsotretinoin tedavisi, karaciğer fonksiyon testleri ve lipid profili normal olan olgulara başlandı. Kadın olgular için ayrıca beta HCG testinin negatif olmasına dikkat edildi.

Çalışma öncesinde yerel etik kurul onayı ve tüm olgulardan yazılı onay alındı.

Akne vulgaris nedeniyle, izotreinoin kullanım endikasyonu konan hastalarda tedaviye $1 \mathrm{mg} / \mathrm{kg} / \mathrm{gün}$ dozda başlandı. Tedavi süresi, 120 $\mathrm{mg} / \mathrm{kg} / \mathrm{gün}$ kümülatif dozuna göre, 16 hafta olarak belirlendi. Tedavi süresi boyunca yan etkiler yönünden her ay olguların karaciğer fonksiyon testleri, lipid profili kontrolleri yapıldı. Kadın hastalara tedavi süresince ve tedavi bitiminden sonra en az iki ay devam etmek üzere etkin bir doğum kontrol yöntemini kesinlikle uygulamaları önerildi. Fotosensitivite riski nedeniyle, tedavi süresince olgulara güneşten koruyucu ajan kullanmaları önerildi.

Hastalara tedavi öncesinde ve 16 haftalık tedavinin bitiminde, toplam 2 kere Hastane Depresyon ve Anksiyete Ölçeği (HAD) uygulandı. HAD hastada anksiyete ve depresyon yönünden riski belirlemek, düzeyini ve şiddet değişimini ölçmek amacıyla Zigmond ve Snaith tarafından geliştirilen bir ölçektir. Toplam 14 soru içermekte ve tek sayılar anksiyeteyi, çift sayılar depresyonu ölçmektedir. Formun Türkçe geçerlilik ve güvenilirliği Aydemir tarafından yapılmış olup, ölçeğin bedensel hastalığı olanlarda depresyon ve anksiyete belirtilerini tarama açısından güvenli olduğu belirlenmiştir. Türkiye'de yapılan çalışma sonucunda anksiyete alt ölçeği için kesme puanı 11, depresyon alt ölçeği için ise 8 bulunmuştur. Buna göre, bu puanların üzerinde alanlar risk altında olarak değerlendirilir. Hastaların her iki alt ölçekten alabilecekleri en düşük puan 0 , en yüksek puan $21^{\prime}$ dir 4 .

HAD Ölçeğinin hastaların, kendi kendilerine okuyup yanıtladıkları bir ölçek olması dolayısıyla, çalışmaya en az lise ve üzeri eğitim düzeyinde olan hastalar alındı.

Verilerin değerlendirilmesinde SPSS for windows 10,0 istatistik paket programı kullanıldı. Karşılaştırmalarda student's t, mann whitney $u$, wilcoxon rank test, ki-kare ve fisher exact test kullanıldı. $\mathrm{P}<0,05$ anlamlı olarak kabul edildi.

\section{Bulgular}

Çalışmamıza izotretinoin tedavisi uyguladığımız 29'u erkek, 60'ı kadın 89 hasta dahil edildi. Yaşları 16 ile 36 arasında değişen hastaların yaş ortalaması 21,54 idi. Hastalar yaşlarına göre 20 yaş altı ve 21 yaş ve üzeri olmak üzere iki gruba ayrıldı. 20 yaş altı hastaların oranı \%44,9 iken, 21 yaş ve üzeri hastaların oranı $\% 55,1$ idi. Hastalar yine eğitim durumlarına göre; lise öğrencisi ve lise mezunu olanlar üniversite öğrencisi ve üniversite mezunu olanlar olmak üzere iki gruba ayrıldı. Eğitim durumlarına göre yapılan sınıflandırmada lise öğrencisi veya lise mezunu olanların oranı $\% 70,8$, yüksek öğrenim öğrencisi veya yüksek öğrenim mezunu olanların oranı \%29,2 idi.

Akne vulgaris tanısıyla 16 hafta izotretinoin ile tedavi edilen hastalarda HAD Ölçeği ile tedavi öncesi ve tedavi sonrası anksiyete ve depresyon skorları belirlendi. Tedavi öncesinde 22 hasta $(\% 24,7)$, tedavi sonrasında ise 17 hasta $(\% 19,1)$ anksiyete alt ölçeğinden eşik üstü skor aldı. Tedavi öncesi $28(\% 31,5)$ hasta, tedavi sonrası ise 22 $(\% 24,7)$ hasta depresyon alt ölçeğinden eşik üstü skor aldı (Tablo 1). Hastaların ortalama anksiyete skoru tedavi öncesi 8,13 , tedavi sonrası 7,87 olarak ölçüldü. Tedavi öncesi ve tedavi sonrası ortalama anksiyete skorları arasında anlamlı fark bulunmadı $(p>0,05)$. Ortalama depresyon skoru ise tedavi öncesi 5,61, tedavi sonrası 5,07 ölçüldü. Tedavi öncesi ve sonrası ortalama depresyon skorları arasında anlamlı fark bulunmadı $(p>0,05)$ (Tablo 2). Hastaların yaş grupları arasında, tedavi öncesi ve tedavi sonrası anksiyete sıklığı bakımından istatistiksel olarak anlamlı bir farklılık bulunmadı $(p>0,05)$. Yine yaş grupları arasında tedavi öncesi ve tedavi sonrası depresyon sıklığı bakımından da istatistiksel olarak anlamlı bir farklılık bulunmadı ( $p>0,05)$.

Hastaların eğitim düzeyleri arasında tedavi öncesi ve tedavi sonrası anksiyete sıklığı bakımından istatistiksel olarak anlamlı bir farklıık yoktu $(p>0,05)$ Eğitim düzeylerine göre, tedavi öncesi depresyon sıklığı istatistiksel olarak anlamlı bir farklılık göstermezken $(p>0,05)$, lise mezunu veya öğrencisi olan grupta tedavi sonrası depresyon sıklığı üniversite mezunlarına göre anlamlı derecede yüksekti $(p<0,01)$.

Kadın ve erkek hastalar arasında, tedavi öncesi ve tedavi sonrası anksiyete sıklığı arasında istatistiksel olarak anlamlı bir farklılık bulunmadı $(p>0,05)$. Yine kadın ve erkek hastalar arasında, tedavi öncesi ve tedavi sonrası depresyon sıkığı bakımından da anlamlı bir farkılık yoktu ( $p>0,05)$.

Tablo 1. Tedavi öncesi ve tedavi sonrası anksiyete ve depresyon sıklığı

\begin{tabular}{|l|c|c|}
\hline & Olgu sayısı & $\%$ \\
\hline Tedavi öncesi anksiyete & 67 & 75,3 \\
Yok & 22 & 24,7 \\
\hline Var & & \\
\hline Tedavi sonrası anksiyete & 72 & 80,9 \\
Yok & 17 & 19,1 \\
Var & 61 & \\
\hline Tedavi öncesi depresyon & 28 & 38,5 \\
Yok & & 31,5 \\
Var & 67 & 75,3 \\
\hline Tedavi sonrası depresyon & 22 & 24,7 \\
\hline Yok & & \\
Var
\end{tabular}

Tablo 2. Tedavi öncesi ve sonrası anksiyete ve depresyon skor ortalamaları

\begin{tabular}{|l|l|c|c|c|c|}
\hline & \multicolumn{2}{|c|}{ Tedavi öncesi } & \multicolumn{2}{c|}{ Tedavi sonrası } & \multirow{2}{*}{. } \\
\hline & ORT & SS & ORT & SS & p \\
\hline Anksiyete skoru & 8,13 & 3,59 & 7,87 & 3,47 &, 448 \\
\hline Depresyon skoru & 5,61 & 3,47 & 5,07 & 3,60 &, 137 \\
\hline
\end{tabular}




\section{Tartışma}

Yapılan çalışmalara göre akne vulgarisi olan hastaların \%30-50'sinde orta derecede anksiyete semptomları, güvensizlik, utanma, sosyal dışlanma düşünceleri saptanmıştır. Bu negatif psikolojik etkiler kadın hastalarda ve yüz tutulumu olan hastalarda daha belirgindir. Yine yapılan birçok çalışma ile etkili bir akne tedavisiyle anksiyete ve depresyon semptomlarında azalma sağlanabileceği gösterilmiştir5,6,7.

AV tedavisi etyopatogenezde bahsedilen faktörlere yönelik olmalıdır. Buna göre bir akne tedavisinde amaçlanan foliküler keratinizasyonu düzeltmek, sebase bez aktivitesini baskılamak, foliküler bakteri populasyonunu azaltmak ve antiinflamatuvar etki oluşturmaktır2,3,8. Akne patogenezinde rol oynayan bütün faktörlere etkili tek ilaç olan izotretinoin, sentetik oral bir retinoiddir ${ }^{1}$. İotretinoin şiddetli nodülokistik aknede, topikal ve diğer geleneksel tedavilere yanıt vermeyen, skar oluşumuna neden olan, psikolojik olarak problem yaratan akne formlarında ve şiddetli seborede yaygın olarak kullanılmaktadı2,3,9.

İotretinoinin kullanıma sunulduğu 1982 yılından beri psikiyatrik yan etkileri gündemdedir. Illk kez, 1982 yılında Meysken tarafından, izotretinoin kullanan bir hastada depresyon semptomları saptandığı rapor edilmiştir. Yine yakın zamanlarda Florida'da izotretinoin kullanan bir erkek hastanın suisidal girişimi bildirilmiştir ${ }^{10}$.

Izotretinoin ve depresyon arasındaki ilişki halen tartışmalı bir konudur. Olgu bildirimleri izotretinoin ve depresif semptomlar arasındaki ilişkiyi desteklerken, kontrollü çalışmalarda herhangi bir korelasyon saptanamamıştır. Kontrollü çalışmalarda izotretinoin kullanan hastalarda depresyon oranı \%0 iken, kontrolsüz çalışmalarda bu oran \%1-1,5 olarak belirlenmiştir. Bu oran toplumdaki \%10'luk depresyon oranının çok altındadır.

Toplumdaki depresyon insidansının yüksek olması, izotretinoin gibi başka nedenlerle tetiklenen depresyonların ayırdedilmesinde güçlüğe neden olmaktadır. İzotretinoin tedavisindeki hastalarda, depresyon tanısı için yapılan çalışmalarda kullanılan standart tanı kriterleri de bulunmamaktadır. İzotretinoinin FDA tarafından onaylanmış klavuzunda depresyon muhtemel yan etkiler arasında bulunmasına rağmen depresyonun hangi nedensel mekanizma ile ortaya çıktığı konusunda da ortak bir görüş yoktur ${ }^{11}$. Geniş serili bir çalışmada izotretinoinin suisidal riskte anlamlı bir artış yapmadığı gösterilmiştir ${ }^{12}$. Bazı yazarlar izotretinoin kullanımı sonrası görülen depresyonun tesadüfi olduğunu, buna karşılık aslında izotretinoinin vücut imajında düzelme ile birlikte anksiyete ve depresyon bulgularında azalma sağladığını ileri sürmüşlerdir 5,13,14,15.

İotretinoinin anksiyete ve depresyon ile ilişkisi olduğu yönünde genel bir kanı olmasına rağmen izotretinoinin depresyon gelişimindeki rolü tam olarak aydınlatılamamıştır. Ann ve arkadaşları 1984-2004 yılları arasında yayınlanan, izotretinoin kullanan hastalarda depresyon yan etkisini araştıran 6'sı prospektif, 3'ü retrospektif toplam 9 çalışmayı incelemiş ve izotretinoin ve depresyon arasında nedensel bir bağlantı olmadığı sonucuna varmışlardır ${ }^{16}$. Bazı vaka sunumları ise izotretinoin ile depresyon ve suisidal davranışlar arasında bağlantı olduğuna dikkat çekmektedir17,18,19. Scheinman ve arkadaşları yaptıkları çalışma sonucunda izotretinoin kullanan 700 hastanın 7'sinde ağlama atakları, keyifsizlik ve anksiyete bulguları saptadıklarını yazmışlardır. Aynı çalışmada bu semptomların izotretinoin dozundan bağımsız olduğu ve antidepresan tedavi gerektirmediği not edilmiştir ${ }^{19}$. İzotretinoin ile depresyon arasındaki bağlantıyı destekleyen tek kontrollu çalışma ise Azoulay ve arkadaşları tarafından yapılmıştır. Bu olgu çaprazlama (case cross-over) çalışmada farklı zamanlarda ilaca maruz kalma durumu değerlendirildiğinden olgu grubu aynı zamanda kontrol grubu olarak alınmıştır. Çalışmada hiç depresyon geçmişi olmayan hastalarda izotretioninin kullanımından sonra depresyon riskinin üç kat arttığı vurgulanmış ve bu sebeple izotretinoin kullanan bireylerin depresyon bulguları açısından sıkı takibi önerilmiştir20.

Biz yaptığımız çalışmada klinik olarak şiddetli (Allen-Smith Skalası'na göre grade 4 ve grade 8 arasında) akne vulgarisi olan ve daha önce topikal akne preparatlarına veya sistemik antibiyotik tedavilerine cevap vermemiş, izotretinoin tedavisi planlanan 89 hastaya, tedavi öncesinde ve sonrasında HAD ölçeği uyguladık. Ölçek sonuçlarına göre hastaların aldıkları skorlar eşik altı ve eşik üstü olarak değerlendirildiğinde; tedavi öncesinde 22 $(\% 24,7)$ hastanın anksiyete alt ölçeğinden eşik üstü, $28(\% 31,5)$ hastanın depresyon alt ölçeğinden eşik üstü skor aldıkları; tedavi sonrasında ise 17 $(\% 19,1)$ hastanın anksiyete alt ölçeğinden eşik üstü ve $22(\% 24,7)$ hastanın depresyon alt ölçeğinden eşik üstü skor aldıkları belirlendi. Bu sonuçlara göre; tedavi öncesi ve tedavi sonrası anksiyete ve depresyon sıklığı arasında istatistiksel olarak anlamlı bir fark yoktu. Yine tedavi öncesi ve tedavi sonrası HAD ölçeği skorlarını karşılaştırdığımızda tedavi öncesi anksiyete skoru ortalama 8,13 iken, tedavi sonrası anksiyete skoru 7,87 ölçüldü; tedavi öncesi depresyon skoru 5,61 iken, tedavi sonrası depresyon skoru 5,07 ölçüldü. Bu sonuçlar karşılaştırıldığında tedavi öncesi ve tedavi sonrası anksiyete ve depresyon skorları arasında istatistiksel olarak anlamlı bir fark görülmedi $(p>0,05)$.

Sonuç olarak; bu çalışmamızdan elde ettiğimiz veriler izotretinoin ile depresyon ilişkisini desteklememektedir. İzotretinoinin depresyon yan etkisini araştıran literatürlere baktığımızda genel olarak ortak bir noktada birleşilmemekle birlikte, izotretinoinin depresyona sebep olduğunu ileri süren çalışmalar daha çok olgu sunumu niteliğindedir ve izotretinoin ile depresyon arasındaki ilişkiyi destekleyen kontrollü çalışmalar sınırlıdır. Buna karşılık izotretinoin ile depresyon arasında anlamlı bir ilişki olmadığı sonucuna varılan çok sayıda retrospektif ve prospektif kontrollü çalışma bulunmaktadır. Ancak yine de izotretinoin tedavisi sırasında, depresif semptomlar geliştiren olguların bulunması tedavi sürecinde hastaların anksiyete ve depresyon gelişimi bakımından yakın takip edilmesinin gerekliliğini göstermektedir.

\section{Kaynaklar}

1. Layton AM, Knaggs H, Taylor J, Cunliffe WJ: İsotretinoin for acne vulgaris: 10 years later: a safe and successful treatment. $\mathrm{Br} J$ Dermatol 1993;129:292-6.

2. Zouboulis CC, Mart JP: Update and future of systemic acne treatment. Dermatology 2003;206:37-53.

3. Gollnick H, Cunliffe WJ, Berson D, et al: Management of acne. J Am Acad Dermatol 2003;49:1-37.

4. Aydemir Ö: Hastane Anksiyete ve Depresyon Ölçeği Türkçe formunun geçerlilik ve güvenilirlik çalışması. Türk Psikiyatri Dergisi 1997;8:280-7.

5. Kellett SC, Gawkrodger DJ: The psychological and emotional impact of acne and the effect of treatment with isotretinoin. $\mathrm{Br} J$ Dermato 1999;140:273-82.

6. Gupta MA, Gupta AK: Depression and suicidal ideation in dermatology patients with acne, alopecia areata, atopic dermatitis and psoriasis. $\mathrm{Br} J$ Dermatol 1998;139:846-50.

7. Rubinow DR, Peck GL, Squillace KM, Gantt GG: Reduced anxiety and depression in cystic acne patients after successful treatment with oral isotretinoin. J Am Acad Dermatol 1987;17:25-32.

8. Webster GF: Combination azelaic acid therapy for acne vulgaris. J Am Acad Dermatol 2000;43:47-50.

9. Katsambas A, Papakonstantınou A: Acne: Systemic treatment. Clin Dermatol 2004;22:412-18. 
10. Meykens FL: Short clinical reports. J Am Acad Dermatol 1982;6:732.

11. Kaymak Y, Kalay M, Ilter N, Taner E: Incidence of depression related to isotretinoin treatment in 100 acne vulgaris patient. Psychol Rep 2006;99:897-906.

12. Jick SS, Kremers HM: Isotretinoin use and risk of depression, psychotic symptoms, suicide and attempted suicide. Arch Dermatol 2000;136:1231-6.

13. Jacobs DG, Deutsch NL, Brewer M: Suicide, depression and isotretinoin: is there a causal ling?. J Am Acad Dermatol 2001;45:168-75.

14. Medansky RS, Handler RM: Dermatopsychosomatics: classification, physiology and therapeutik approaches. I Am Acad Dermato 1985;5:125-36

15. Bickers DR, Saurat JH: Isotretinoin: a state of the art conference. J Am Acad Dermatol 2001;45:125-8.
16. Ann LM, Lee TZ: Depression and suicidal behavior in acne patients treated with isotretinoin: a systematic review. Semin Cutan Med Surg 2005;24:92-102

17. Bigby M, Srern RS: Adverse reactions to isotretinoin: a report from the adverse drug reaction reporting system. J Am Acad Dermatol 1988:18:543-52.

18. Bachmann C, Grabarkiewicz J, Theisen FM, Remschmidt H: Isotretinoin, depression and suicide ideation in an adolescent boy. Pharmacopsychiatry 2007;40:128-31.

19. Scheinman $P L$, Peck GL, Rubinow DR, et al: Acute depression from isotretinoin. J Am Acad Dermatol 1990;22:1112-4.

20. Azoulay L, Blais L, Koren G, LeLorier J, Bérard A: Isotretinoin and the risk of depression in patients with acne vulgaris: A case-crossover study. J Clin Psychiatry 2008;69:526-32 